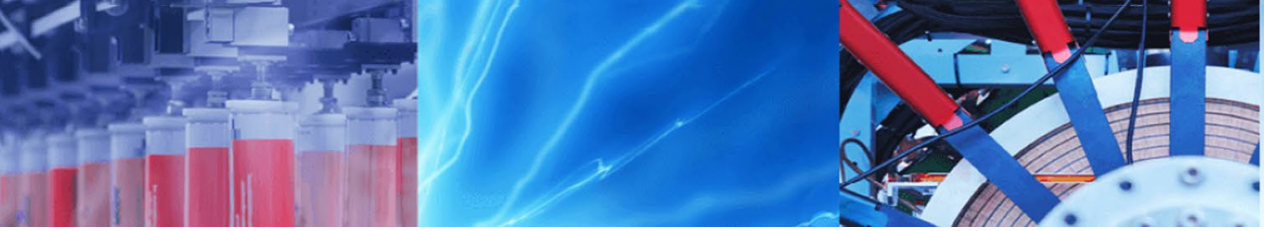

Short Communication

\title{
How do climate risks affect corporations and how could they address these risks?
}

\author{
Hans Sanderson ${ }^{1}\left[\right.$ D Diana Morales Irato $^{2} \cdot$ Nieves Peña Cerezo $^{3} \cdot$ Harm Duel $^{2} \cdot$ Pedro Faria $^{4} \cdot$ Efren Feliu Torres $^{3}$
}

Received: 28 August 2019 / Accepted: 19 November 2019 / Published online: 28 November 2019

(c) Springer Nature Switzerland AG 2019

\begin{abstract}
Physical and transitional risks resulting from climate change are already inducing significant direct and indirect impacts on organizations - such as damages to assets, disruption to supply chains, or shifts in supply and demand for certain commodities, products or services. The current short-termism of most companies suggests the importance of raising awareness among the private sector about the potential risks of climate change. However, companies increasingly are reporting and disclosing climate risks and associated costs as asked for benchmarking by financial institutions and to comply with regulations with respect to sustainable finance. A guidance on how to do a climate risk assessment and to estimate the costs of physical climate risk as well as transitional and systemic risk concerning their operations and value chain management is lacking. This paper presents a stepwise blueprint on climate risk assessment and financial disclosures that support companies on reorienting capital flows towards more sustainable investments and with their disclosure process to foster transparency and long-termism in financial and economic activity in line with the action plan on sustainable finance adopted by the European Commission in March 2018 to achieve sustainable and inclusive growth.
\end{abstract}

Keywords Climate risk · TCFD · Private sector · Finance

\section{Introduction}

It is widely recognized that the financial system has a significant responsibility on current state of the health of the planet, as it typically does not internalize its environmental externalities into the price structure. The resulting economic system is unsustainable, with climate change and a carbon-dependent economy as an example of what needs to be changed [1]. At the top of the climate and business agenda of the past 3 years, two very important issues have emerged. The first is a need to shift the financial flows to more climate friendly and decarbonised investment portfolios and low-carbon economy, which is one of the pillars of the Paris Agreement. In clean energy alone, there is an $€ 11.2$ trillion investment pipeline waiting to be delivered in Europe by 2030 [2, 3]. The second is climate disclosure and the need for transparency of the exposure of financial actors and their assets to climate risks so they can be managed. This context led to the creation of the Task-force on Climate-related Financial Disclosure (TCFD) under the Financial Stability Board (FSB) [4], as well as The European Commission's plans for sustainable finance [5].

This paper focuses on developing effective climate risk assessment, management and communication needed to deliver the Paris Agreement. While the information requirements needed at the level of the financial system have been clarified by the TCFD Guidance documents, the information and procedural requirements for sound climate risk assessment at company level are not yet consolidated. This, in a way, configures a situation

$\triangle$ Hans Sanderson, sanderson@envs.au.dk| 'Department of Environmental Science, iClimate, Aarhus University, 399 Frederiksborgvej, 4000 Roskilde, Denmark. ${ }^{2}$ Department of Water Resources and Delta Management, Deltares, Boussinesqweg 1, 2629 HV Delft, The Netherlands. ${ }^{3}$ Energy and Environment Division of Tecnalia Research \& Innovation, TECNALIA, Edificio 700, Parque Tecnológico de Bizkaia, 48160 Derio, Spain. ${ }^{4}$ CDP, 4th Floor Plantation Place South - 60 Great Tower Street, London EC3R 5AD, UK. 
of "house built from the top down", as risk disclosure can only be as good as the risk assessment on which it relies. The upper policy and financial system layers have to be based on sound assessments at the corporate level (Fig. 1).

\section{Methodology}

We have reviewed current risk assessment approaches and disclosure processes, including climate risk assessment approaches [6-8]. We have worked through interviews and workshops with industry to co-develop a blueprint

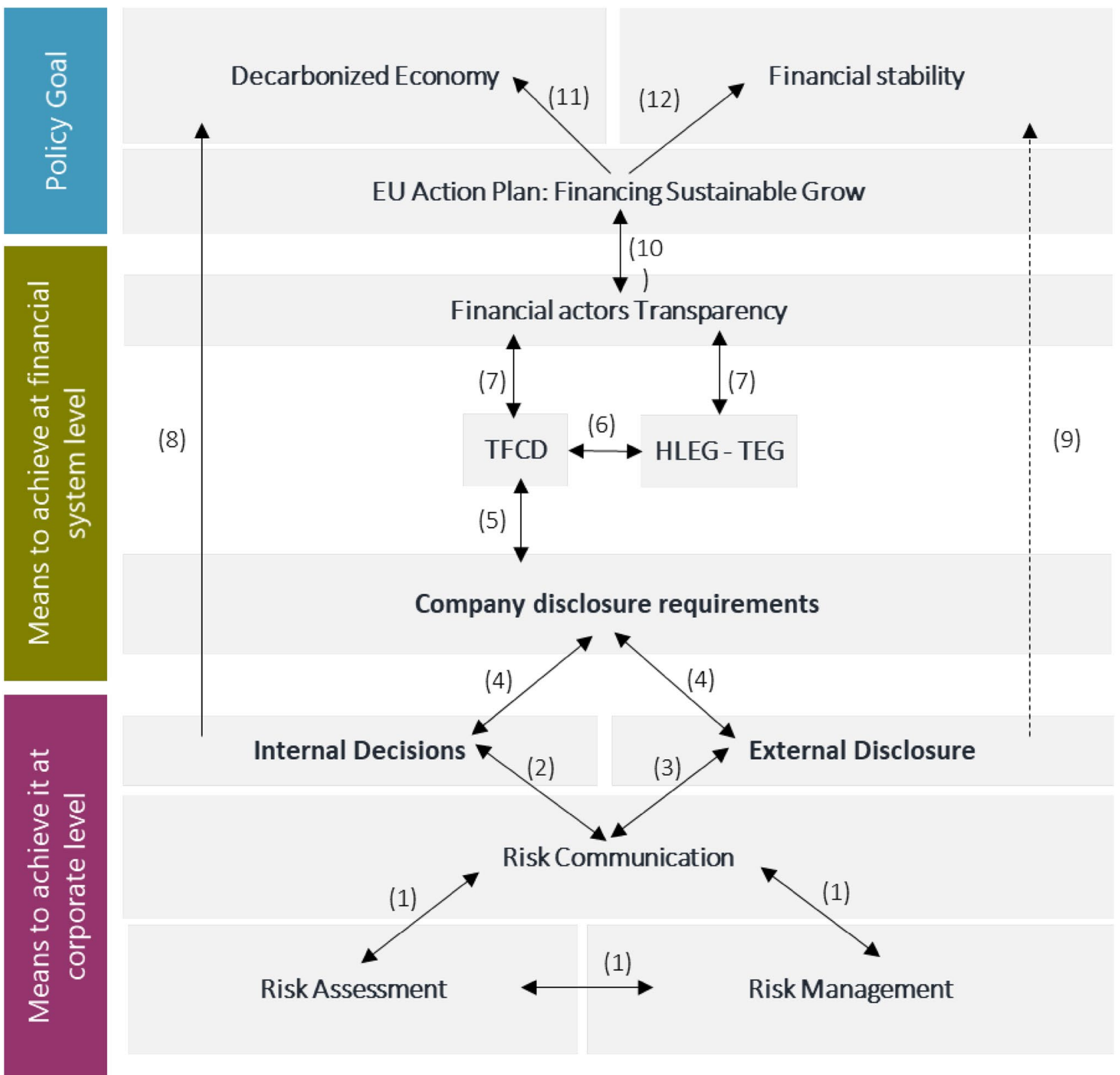

Fig. 1 Climate-related assessment and disclosure structure: (1) at corporate level assessing, managing and communicating risks; (2) internal risk communication to incorporate opportunities into strategies; (3) external disclosure to stakeholders; (4) company disclosure requirements set at the financial system-level; (5) and these have been set by the market in the TCFD; (6) the HLEG-TEG work, driven by the EU; (7) and both TCFD and HLEG-TEG transparency requested from the financial actors; (8) company internal decision-making to decarbonize the economy; (9) public disclosure of climate-related risks affects financial stability; (10) financials actors transparency is a new requirement being enacted from the policy level; (11) which seeks to support both the broad policy goals and; (12) guaranteeing the stability of the financial system 
for climate risk assessment and disclosure and have conceptually validated it with an industry group, representing food industry, consumer products industry, energy sector and transport sector (Fig. 2).

\section{Results}

\subsection{Transparency and climate risk disclosure}

Currently, most disclosures rely frequently on qualitative rather than quantitative information. At the global level, the FSB's TCFD is the first industry-led framework with the potential to become a "new norm" of climate disclosure moving towards more quantitative assessments $[9,10]$. The TCFD framework [10] is developed to make it easier

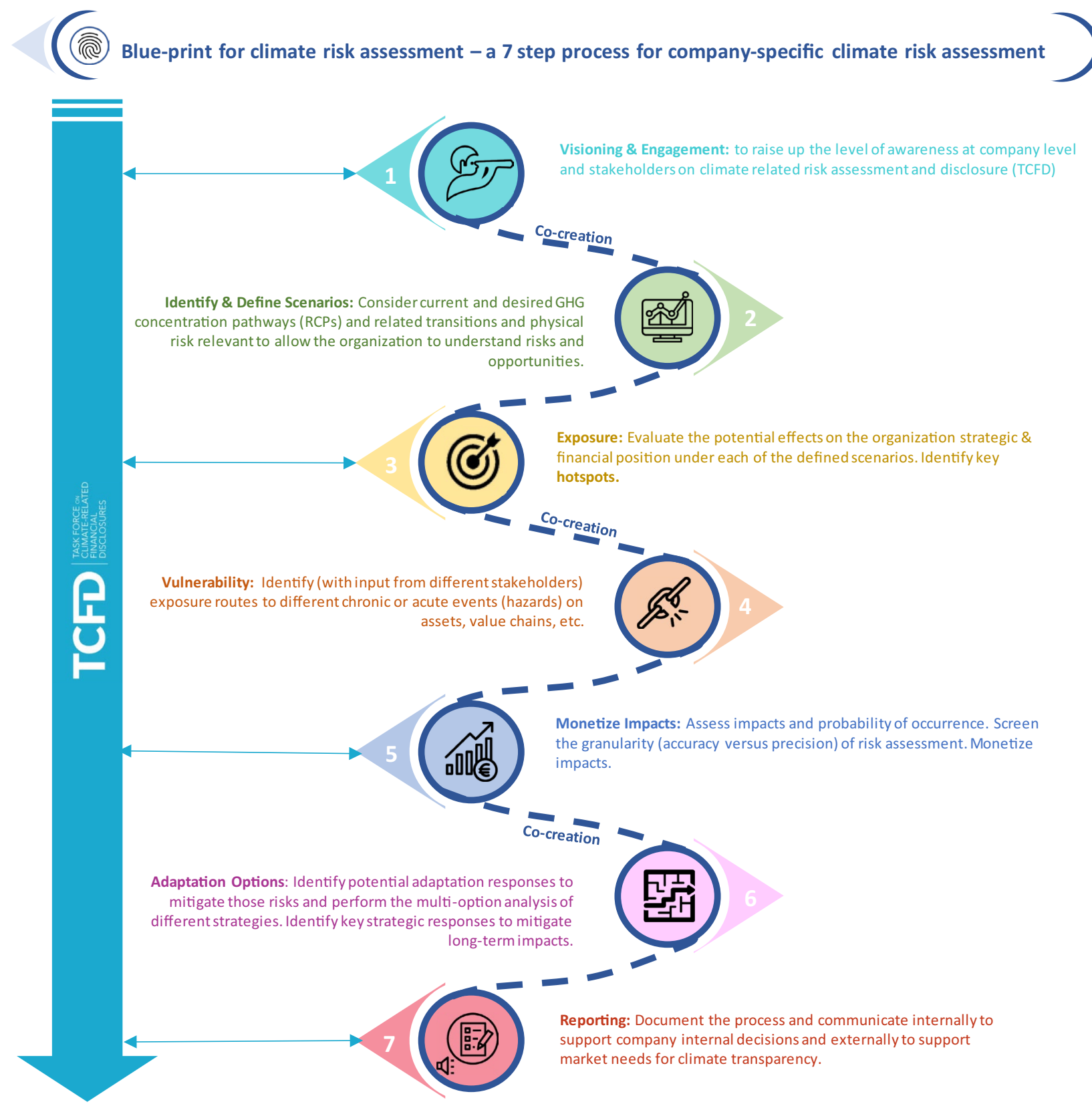

Fig. 2 Initial climate risk assessment iterative process 
to assess and disclose climate-related financial risks in the market. The TCFD [8] highlights the greatest needs for guidance and research related to a common conceptual framework and a standard set of metrics for assessing and disclosure of climate risks and opportunities; they recommend that: (1) Corporations need help to develop their own scenarios; (2) they should mobilize people across their organization and foresee potential climate-related risk and possibilities; (3) new indicators and metrics are needed to quantify the risks and opportunities as well as market transitions [8].

Efforts have also been pursued at the national level, notably, Article 173 of France's Energy Transition Law [11], requiring all major institutions (listed companies but also banks and institutional investors) to evaluate, report and address their exposure to long-term climate-related financial risks. There is hence a need for capacity-building and development of best practice by all stakeholders involved both at the corporate and governmental level to ensure that risks are accurately assessed, managed and disclosed [12].

\subsection{Climate risk management at the finance sector level}

Risk assessment and financial disclosures nowadays are typically short-term focused and the models used by financial analysts rarely look beyond 1-3 year timehorizon [13]. To avoid stranded assets due to climaterelated risks, the market needs to apply more forwardlooking tools that enable them to factor future shifts into their decision-making $[14,15]$. Climate change is an area where sustainable finance is moving towards a sustainability disclosure regime; yet, it is still a clear case of the "tragedy of the horizon", according to the Chair of the Financial Stability Board, Mark Carney: The horizon for monetary policy extends out to two to three years. For financial stability, it is a bit longer, but typically only to the outer boundaries of the credit cycle-about a decade. In other words, once climate change becomes a defining issue for financial stability, it may already be too late." [14]. Climate risks are still not well understood, appreciated, and acted upon in the global business community [16, 17]. Goldstein et al. [18] found empirical evidence for this after reviewing 1600 + corporates adaptation strategies. They found that assessment of climate-related costs was irregular, varying, underestimating supply chain and broader societal impacts. The costs were represented as upfront investments and often with no assessment of the cost of inaction [17]. For the past 3 years, climate change has been recognized as the most significant global risk according to the World Economic Forum 2019 risk report [19]. In response, the European Commission appointed the High-Level Expert Group (HLEG) on Sustainable Finance Dec 2016 [3]. The HLEG has put forward a set of recommendations and priorities to enable investors to invest in sustainable finance opportunities and suggests that companies shall disclose their climate-related risks. Action \#9 in the EU Action Plan on Sustainable Growth will assess EU legislation on public corporate reporting, including the non-financial information (NFI) Directive and determine if the $\mathrm{NFI}$ should be amended to include climate risks. Asset managers and institutional investors will be asked to disclose how they consider sustainability factors in their decision-making process and in particular for regarding exposures to climate change-related risks moving forward [20]. In June 2019, the European Commission published its technical Taxonomy report outlining details on how the financial instruments should be developed to support the achievement of the Paris Agreement targets [21].

\subsection{Climate risk assessment blueprint}

Dietz et al. found that the global business community face value assets at risk from climate change of up to US\$24 trillion/year [20]. If emissions remain flat or increase at $2 \%$ a year, then total cost increases to at least US\$89 trillion and potentially up to US\$ 535 trillion-up to $30 \%$ of manageable assets globally may be at risk [22]. We developed a blueprint for climate risk assessment based on a series of workshops with a handful of multinational corporations, to help companies internalize the environmental externalities related to climate change as well as facilitate more long-term climate smart strategic planning informed by risk analysis and identification of opportunities. The blueprint provides an outline of a simple but powerful 7-step methodological framework to facilitate the implementation of effective climate risk assessment, management and communication - both externally (disclosure) and internally (management and decision-making procedures).

Companies need support to assess and manage risks and opportunities quantitatively. Better access to tailored and downscaled climate data as well as information of policy and transitional developments will enhance how climate-related risks are assessed, priced, and managed. Investors will make better informed decisions on where and how they want to allocate their capital. Lenders, insurers and underwriters will be better able to evaluate their risks and exposures over the short, medium, and long-term. There will be sectorial differences and challenges as well as sectorial differences in the perception of risks, which will shape the more detailed discussions, and analysis in each step. The developed blueprint is a generic approach for all sectors. 


\section{Discussion and conclusions}

Assessment of extreme climate-related physical risks and systemic transitional risks should be used by companies to develop new ways of doing business. In both cases, costs can be curtailed, and profits can be made from the volatility in value assets. Climate will increasingly be a strategic factor in business decision-making processes based on risk and opportunity analysis. Corporate disclosure of climate-related risks will gain momentum and importance in corporate financial, ESG and CSR, and other reporting and disclosure. TCFD represents an opportunity to bring climate-related financial reporting to a mainstream audience. Its promise is that increasing transparency makes markets more efficient, and economies more stable and resilient. TCFD is driven by market demand by investors, insurers and the supply and value chain of companies (bottom-up) and engaged extensively with key stakeholders to ensure that it build on existing work and produces recommendations that can be used by the private sector, globally. On the other hand, there are also policy-driven developments in the field, e.g. the French Art 173 and the emerging EU policies. There is a significant and growing demand both from the market and the policy side to disclose climaterelated risks in accordance to TCFD recommendations, and thus also a requirement for companies to assess and manage climate risks. To meet these demands and to improve and speed-up the maturing of climate risk assessment and disclosure, we suggest:

1. Invest in the early adoption of TCFD recommendations by as a wider group of stakeholders as possible, e.g. CDP adoption of TCFD recommendations to its questionnaires will bring them to over 7000 companies around the globe;

2. Build continuous momentum on the adoption of TCFD recommendations, namely by promoting its adoption and/or reference in regulatory frameworks and national policies. These do not have to mandate reporting or disclosure, instead they can focus on other levels that might drive demand for this type of assessment, for example, by imposing conditions on financial actors' fiducial duty of care;

3. Support the adoption of TCFD recommendations by companies, by providing best in class examples, case studies, peer-learning and training;

4. Engage early enough in standardization efforts of climate risk assessment, namely in efforts related with issues of access to data, establishment of methods and provision of accessible tools for climate risk assessments;
5. Support the development of sector/company/site specific scenarios, which should be highly contextual, and based on the views and values of individual corporations;

6. Mobilize and raise awareness on climate-related risk management and disclosure;

7. Support the collaboration between science-based climate service providers, NGOs, investors and companies to co-develop new indicators and metrics needed to properly quantify risks.

There is a growing need for development of robust quantitative and science-based evaluation tools on corporation's climate-related risks and to develop tools that are forward looking on the social and economic repercussions of climate change for corporations to deliver the Paris Agreement.

Acknowledgements European Community EIT Climate-KIC and the companies we have worked with in workshops to develop the research.

\section{Compliance with ethical standards}

Conflict of interest On behalf of all authors, the corresponding author states that there is no conflict of interest.

\section{References}

1. EU-COMM-2018-773: https://ec.europa.eu/clima/sites/clima/ files/docs/pages/com_2018_733_en.pdf. Accessed 1 July 2019

2. IEA (2014) https://www.iea.org/newsroom/news/2014/june/ world-needs-48-trillion-in-investment-to-meet-its-energ y-needs-to-2035.html. Accessed 1 July 2019

3. EU Commission on sustainable finance https://ec.europa.eu/ info/business-economy-euro/banking-and-finance/sustainabl e-finance_en. Accessed 1 July 2019

4. FSB TCFD https://www.fsb-tcfd.org/about/\#. Accessed 1 July 2019

5. EU Commission Sustainable finance action plan https://ec.europ a.eu/info/publications/180308-action-plan-sustainable-growt h_en. Accessed 1 July 2019

6. Haasnoot M, Kwakkel JH, Walker WE, ter Maat J (2013) Dynamic adaptive policy pathways: a method for crafting robust decisions for a deeply uncertain world. Glob Environ Change 23:485-498. https://doi.org/10.1016/j.gloenvcha.2012.12.006

7. Ray P, Brown C (2015) Confronting climate uncertainty in water resources planning and project design: the decision tree framework. The World Bank

8. TCFD report (2016) Advancing TCFD guidance on physical climate risks and opportunities: https://www.physicalclimaterisk. com/index.html. Accessed 1 July 2019

9. Christophers B (2017) Climate change and financial instability: risk disclosure and the problematics of neoliberal governance. Ann Am Assoc Geo 107:1108-1127

10. TCFD final report 2017 https://www.fsb-tcfd.org/publications/ final-recommendations-report/. Accessed 1 July 2019

11. Art. 173 https://www.legifrance.gouv.fr/eli/loi/2015/8/17/DEVX1 413992L/jo\#JORFARTI000031045547. Accessed 1 July 2019 
12. Campiglio E, Dafermos $Y$, Monnin P, Ryan-Collins J, Schotten G, Tanaka M (2018) Climate change challenges for central banks and financial regulators. Nat Clim Change 8:462-468

13. Biagini B, Miller A (2013) Engaging the private sector in adaptation to change in developing countries: importance, status and challenges. Clim Dev 5(3):242-252. https://doi. org/10.1080/17565529.2013.821053

14. Carney $\mathrm{M}$ (2015) Breaking the tragedy of the horizon-climate change and financial stability, 29 Sep 2015, https://tinyurl.com/ yapkmeam

15. Ray PA, Bonzanigo L, Wi S, Yang YCE, Karki P, García LE, Rodrigues DJ, Brown CM (2018) Multidimensional stress test for hydropower investments facing climate, geophysical and financial uncertainty. Glob Environ Change 48:168-181

16. Surminski $S$, Di Mauro M, Baglee A, Connell R, Hankinson J, Haworth A, Ingirige B, Proverbs D (2018) Assessing climate risks across different businesses and industries: an investigation of methodological challenges at national scale for the UK. Philos Trans R Soc A Math Phys Eng Sci 376 (2121). ISSN 1364-503X https://doi.org/10.1098/rsta.2017.0307

17. Global Compact (2016) https://www.unglobalcompact.org/ what-is-gc/our-work/environment/climate. Accessed 1 July 2019
18. Goldstein A, Turner WR, Gladstone J, Hole DG (2019) The private sectors' climate change risk and adaptation blind spot. Nat Clim Change 9:18-25

19. World Economic Forum Risk Report (2019) https://www.wefor um.org/reports/the-global-risks-report-2019. Accessed 1 July 2019

20. Dietz, S., Bowen A., Dixon C., Gradwell (2016). Climate value at risk of global financial assets. Nature Climate Change, Letter 4/42016. DOI 10.101338/NCLIMATE2972

21. EU Commission (2019) Taxonomy report: https://ec.europa.eu/ info/publications/sustainable-finance-teg-taxonomy_en\#19061 8. Accessed 1 July 2019

22. Hansen J, Sato M, Kharecha P, von Schuckmann K, Beerling DJ, Cao J, Marcott S, Masson-Delmotte V, Prather MJ, Rohling EJ, Shakun J, Smith P, Lacis A, Russell G, Ruedy R (2017) Young people's burden: requirement of negative $\mathrm{CO}_{2}$ emissions. Earth Syst Dyn 8:577-616. https://doi.org/10.5194/esd-8-577-2017

Publisher's Note Springer Nature remains neutral with regard to jurisdictional claims in published maps and institutional affiliations. 